\title{
NEW DESIGN HEURISTICS IN THE DIGITAL ERA
}

\author{
X. Jin ${ }^{1, \otimes}$ and H. Dong ${ }^{2}$ \\ ${ }^{1}$ Tongji University, China, ${ }^{2}$ Loughborough University, United Kingdom \\ $\bowtie$ jinxn@tongji.edu.cn
}

\begin{abstract}
In the digital era, products' forms do not necessarily follow their function. Design fixation may happen when a designer attempts to generate diverse concepts. New design heuristics for digital design were extracted to support designers in the early conceptual design stage. Ten design heuristics were extracted from 998 RedDot award-winning concept designs (2013-2017) through a five-step process. It was preliminarily tested by four practitioners and proved to have positively influenced their conceptual design.
\end{abstract}

Keywords: digital design, design methods, big data analysis

\section{Introduction}

Design is an important activity for innovation (Design Council, 2018a). Design innovation is an effective pathway to improving human's well-being and enterprise competitiveness (Design Council, 2018b). Innovation and technological change from 3D printing to artificial intelligence offer opportunities for a brighter future (Design Council, 2018b). Digital design is the fastest growing sector of the design economy. Firms in this sector experienced an $85 \%$ growth in turnover between 2009 and 2016, reflecting the growing importance of digital design to the UK (Design Council, 2018b). However, in the digital era, products' forms do not necessarily follow their function; generating a diverse range of ideas may prove even more challenging: designers can become 'fixated' (Vasconcelos and Crilly, 2016; Jansson and Smith, 1991) (i.e. their attention is focused on a single past example or on one new idea). The ability to take a problem and generate multiple, varied solutions that can lead to new, creative outcomes is often referred to as concept generation or ideation (Simon, 1996). A common technique for ideation in industry is traditional team brainstorming (Osborn, 1963) or its variants such as 'brainwriting' (e.g. developing a large quantity of ideas). Designers naturally generate ideas, even without tools (Purcell and Gero, 1996); these natural approaches are developed based on designers' experiences and preferences for problem-solving (Kirton, 2004). Despite the emphasis on creative exploration, industrial designers have been shown to experience limitations when attempting to generate diverse concepts (Bruseberg and McDonagh-Philp, 2002).

'Design heuristics (DHS)' are defined as cognitive 'shortcuts' that point toward useful design patterns (Daly et al., 2012; Yilmaz et al., 2010; Yilmaz et al., 2011; Yilmaz et al., 2016). DHS as a tool can help boost designers' creativity in the early design phases (Yilmaz et al., 2016). Since the middle of the $20^{\text {th }}$ Century, different DHS have been developed, e.g. general ones such as SCAMPER (Eberle, 1971), TRIZ (Ilevbare et al., 2013), and 77 Design Heuristics (Yilmaz et al., 2016). Some scholars developed DHS for specific areas, such as DHSfX (design for one-handed 
use) (Hwang and Park, 2018) and DHS for additive manufacturing (Bloesch-Paidosh and Shea, 2019). On the other hand, design heuristics are associated with effective innovation in both engineering and industrial design domains (Yilmaz et al., 2015). However, existing research about DHS has limitations: 1) the data are not up to date (mainly from 2001 to 2009), and most are structural design heuristics for the industrial design area (e.g., expand or collapse, flatten, and extend surface, etc.) (Yilmaz et al., 2016; 2) service-based products are not included (Yilmaz et al., 2016). Because heuristics are based upon experiences, new design goals and contexts may give rise to innovation in heuristics as the field of product design (and designers' experiences) have changed dynamically over time (Yilmaz et al., 2016). Besides, the rapid evolution of information and communications technologies (ICT) has changed the way in which companies innovate and generate value for their customers (Calabretta and Kleinsmann, 2017). Technical advances have triggered an opportunity for design innovation to generate a wealth of new products (Dove et al., 2017).

New Design Heuristics are needed for the fast-developing digital era. This study aims to adding digital design heuristics covering service-based products and new technology applications such as 3D-Printing, Internet of Things (IoT), and Machine Learning (ML).

\section{Research methods}

\subsection{Data collection}

The new design heuristics were extracted from professional award-winning designs. Some related studies have employed award-winning designs as a data source (Yilmaz et al., 2016; Han et al., 2019; Wang, 2016; Yilmaz et al., 2011). Using the web crawler technology (Castillo, 2005), we gathered 998 award-winning product and service design data from the RedDot Concept Design Awards website, covering the period between 2013 and 2017, and these data were recorded in Excel. Each entry includes color images, product names, product categories, textual descriptions and the types of awards (e.g., Best of the Best, Winner, Honor Mention).

RedDot Design Concept Awards (RedDot) were targeted because of its comprehensiveness: 1) RedDot includes more than 34 design categories (e.g., Smart, Interaction, Recreation, etc.). 2) The award-winning products/services are selected from the 12,000 submissions from more than 60 countries every year; 3 ) the RedDot Concept Design Awards' Judging Criteria include many aspects (e.g., degree of innovation, aesthetic quality, realisation possibility, functionality, emotional content, and impact) and emphasise the innovation aspect (RedDot, 2020). RedDot is ranked the 1st in the survey of the ranking of design awards (Self, 2014).

\subsection{Data analysis and extraction}

Two researchers were involved in the data extraction processes. One was a professional designer who has bachelor's and master's degrees in industrial design, and he has won design awards including RedDot, IDEA, and IF, with 2 years' work experience in Microsoft and NetEase for digital design, and has 5 years' research experience in product design innovation. The other has a master's degree in management science and engineering, and has won several RedDot awards. She works in the Chinese Alibaba Group and has 5 years' work experience in information analysis and management. They worked together to extract the new design heuristics. When they had different opinions, they discussed to reach agreement. The description of this extraction procedure is illustrated in Figure 1.

Step 1. Narrowing the data sources' scope. By reviewing every award-winning designs' images and short introductions, the two researchers quickly selected designs which were suitable. They focused on extracting the design heuristics in digital products and service innovation areas. Hence, many of the traditional industrial designs' structure innovation and visual designs were excluded, and only those with digital features were retained.

Step 2. Reading every award-winning designs' images and text descriptions to understand the design and its function. The two researchers wrote down keywords to define these design's critical innovative functions and features. Using QSR NVivo 12® (one of the popular qualitative analysis software) 
(Bazeley and Jackson, 2013; Edhlund and McDougall, 2019), the researchers were able to extract critical words for design heuristic.

Step 3. If more than three products share key functions and features, they were grouped together, and design heuristics were extracted based on these groups.

Step 4. New design heuristics were then defined from these different groups.

Step 5. The initial design heuristics were checked to see whether they were easy to understand and remember, through discussion between the two researchers, with consultation to design lecturers.

998

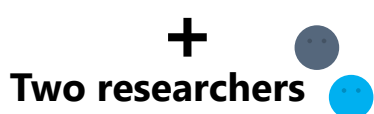

Preparation

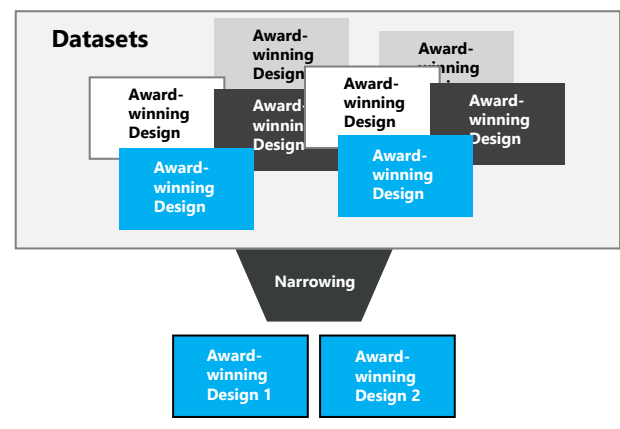

Step 1 Focusing on digital design
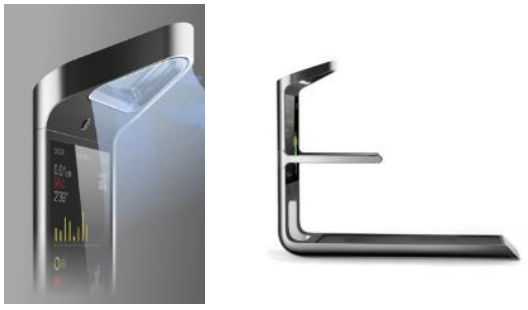

It shows a treadmill, which is designed with infrared thermal imaging technology that displays the user's health information in real time.

Step 2 Reading through descriptions

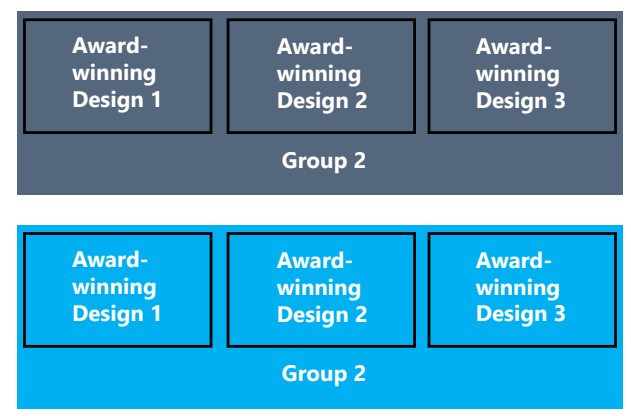

Step 3 Grouping similar designs

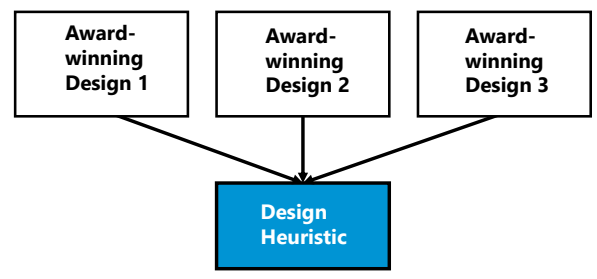

Group1

Step 4 Extracting heuristics
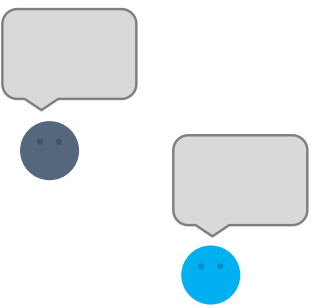

Step 5

Communicating heuristics

Figure 1. The 5-step process of extracting design heuristics

\subsection{Design heuristic examples}

In total 10 design heuristics for digital design were extracted. In order to make the design heuristics easy to understand and remember for students and practitioners, we included not only textual descriptions but also images. These design heuristics were general and brief so that design practitioners' imagination and creativity would not be restrained (by details). Below are two examples.

\subsubsection{DHS 1: Utilizing display technology}

This means utilizing the image display technology to rebuild the product's using styles. Figure 2 (a) shows a LED net that keeps track of the scores and the game situation through an infrared ray sensor. The information is displayed via the optical fibre net. Figure 2 (b) shows an intuitive mirrorless camera with interchangeable lens. It combines the functionality of a high-end camera with a userfriendly interface that makes the camera more accessible for novice and intermediate photographers. Figure 2 (c) shows that Optic gives cyclists the visual information to make safer decisions on the road by integrating a heads-up display, front and rear cameras and 360-degree proximity and collision 
detection. This allows users to focus on the road ahead with full awareness of their surroundings and potential risks.

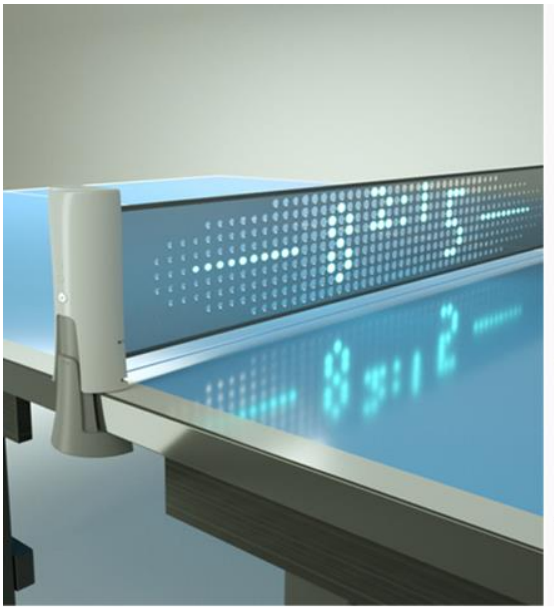

(a) SMART NET

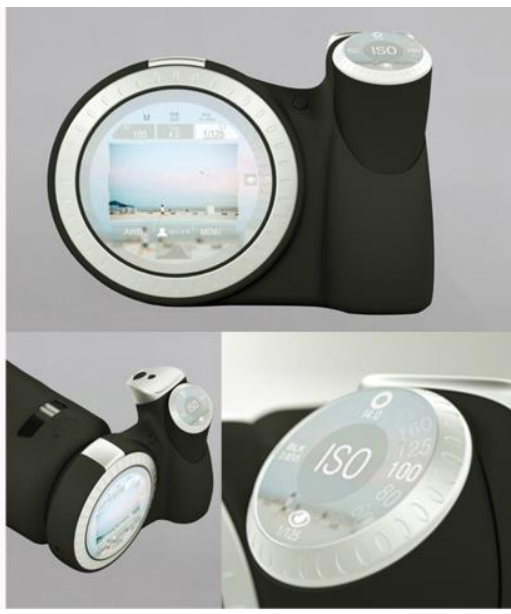

(b) Sphaera Camera

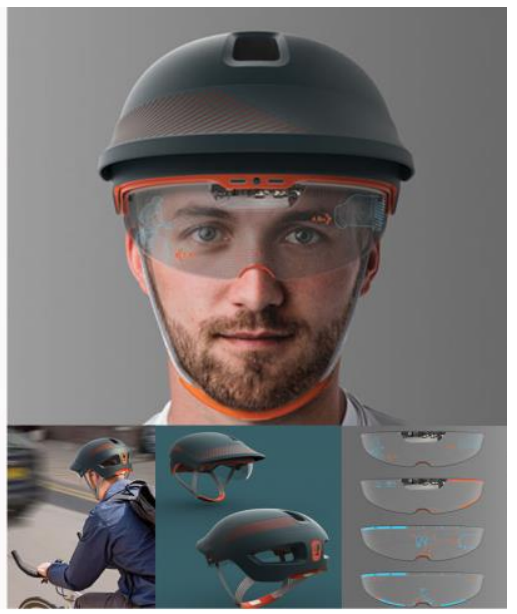

(c) Optic

Figure 2. Design examples of utilizing display technology

\subsubsection{DHS 2: Manage and control remotely}

Through connecting to smartphone apps, machines will become more intelligent, and users may manage and control these devices from a long distance. Figure 3 (a) shows that Retriever makes parking easier and faster. You can search for, find, book and pay for a parking space anywhere via your smartphone, using the Retriever city parking and reserving app and meters.

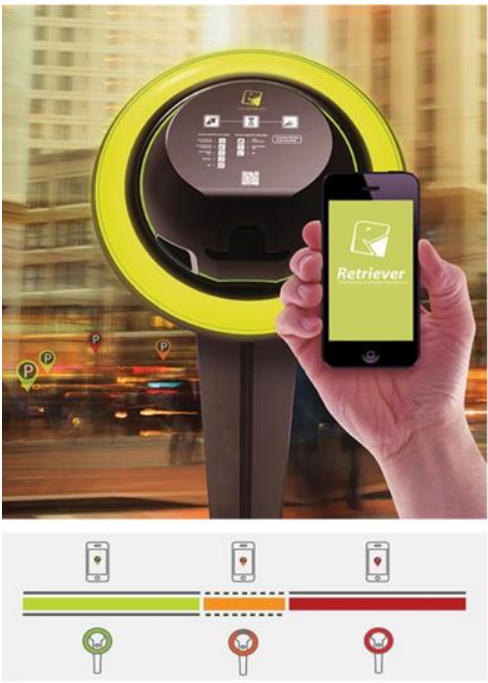

(a) Retriever

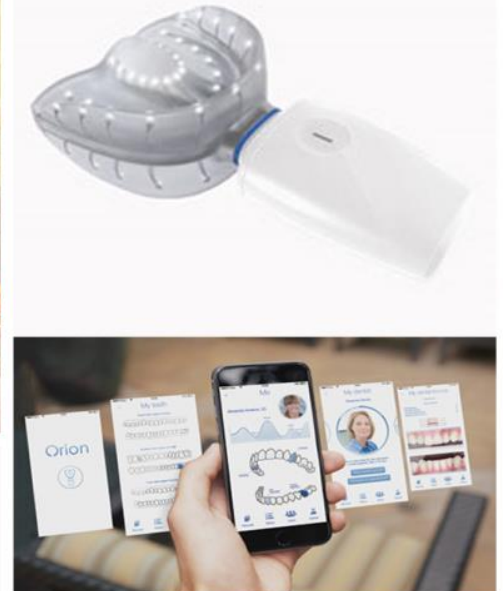

(b) Orion Dental Camera

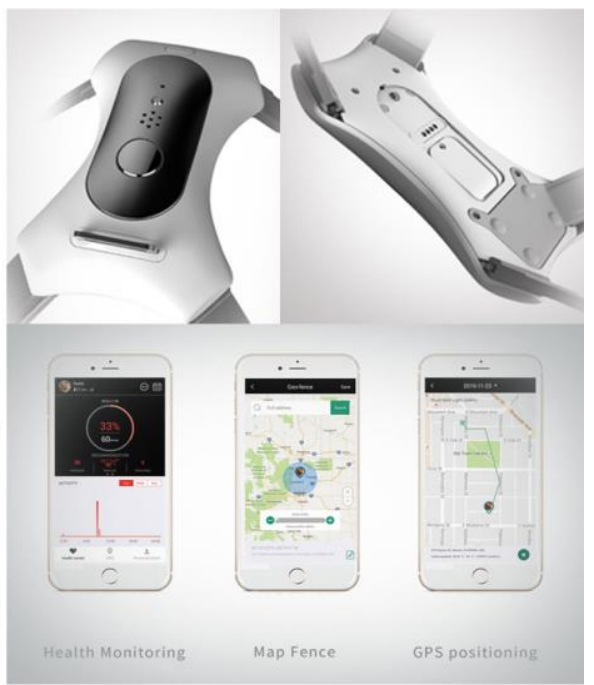

(c) PETTI

Figure 3. Design examples of managing and control remotely

Figure 3 (b) shows that Orion Dental Camera is a consumer camera that provides dental monitoring for the entire family. Through software analysis, it matches pictures recorded of the teeth over time, and through a mobile application, it notifies the user if changes are detected.

Figure 3 (c) shows a wearable smart device for dogs to improve the experience of dog-walking. It includes functions such as remote calling, GPS positioning, health monitoring, and bark control. 


\section{Results}

Figure 4 shows the ten extracted new Design Heuristics.

\section{Design}

\section{Heuristics 10}
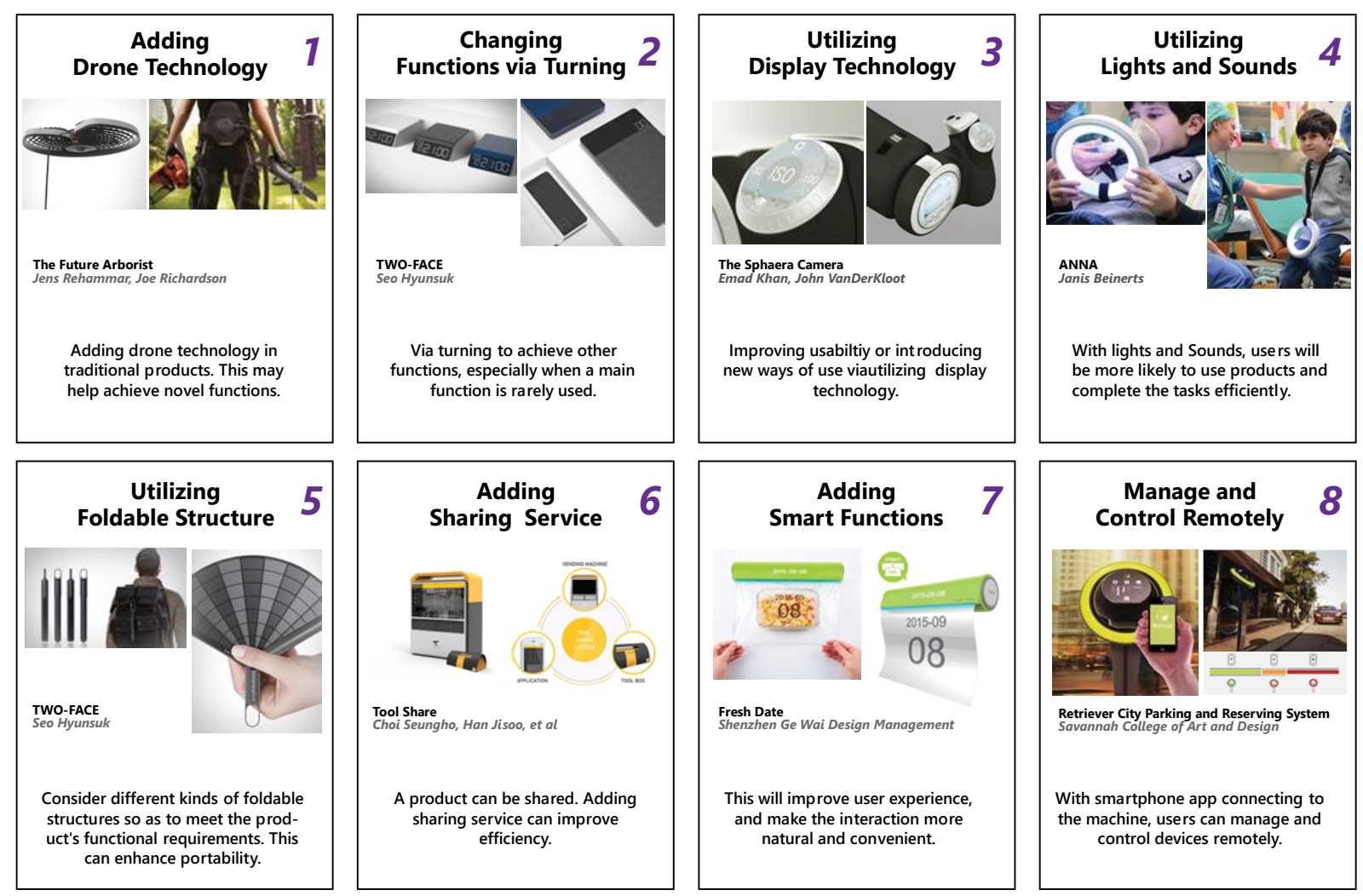

Retriever City Parking and Reserving System
Savannah College of Art and Design With smartphone app connecting to
the machine, users can manage and control devices remotely.
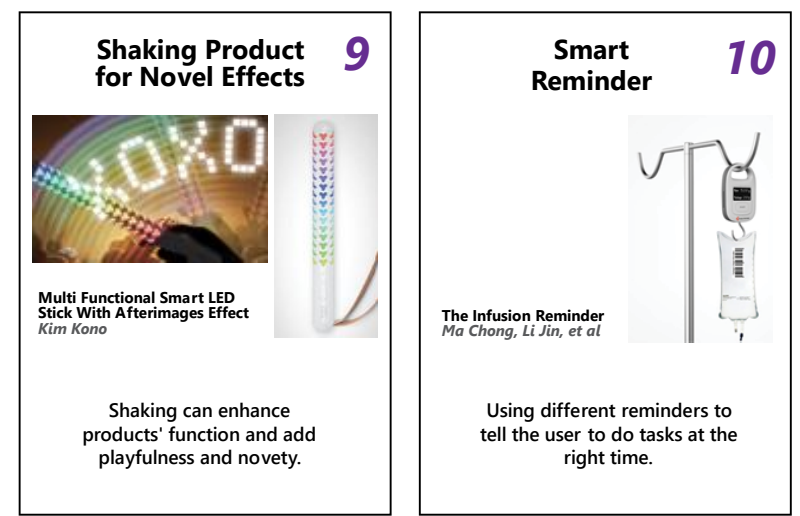

Figure 4. Ten new design heuristics

\section{Preliminary evaluation}

In order to test whether our new DHS can help designers to generate novel ideas, we did a preliminary evaluation.

\subsection{Participants}

Four volunteers with industrial design background participated in the preliminary evaluation, including one master student, one Ph.D. student, and two industrial design teachers. 


\subsection{Task}

To evaluate the effectiveness of the new design heuristics for concept generation, the following design brief (Figure 5) was given to the volunteers. The brief was taken from the SAMSUNG DESIGN PRIZE 2019.

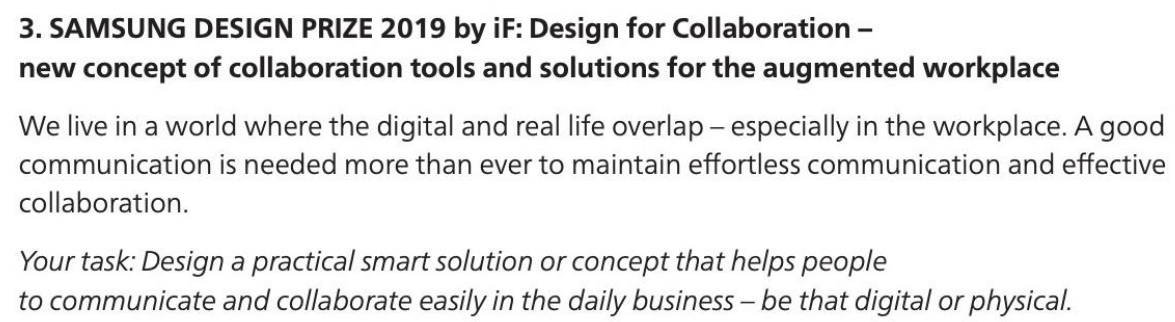

Figure 5. Experimental design task

The master student was asked to answer the design brief within 60 minutes, using brainstorming and the new design heuristics, and communicate his concepts using sketches and text descriptions. The other volunteers were asked to answer the same design brief within 30 minutes, generating as many ideas as possible, identifying which DHS they used, and communicate their concepts using sketches and text descriptions. All the volunteers were allowed to use their quiet working space during the time, without influencing each other.

\subsection{Evaluation}

Each idea was evaluated employing the evaluation criteria: novelty. Novelty (Tsenn et al., 2014, Vasconcelos and Crilly 2016) has been widely used for evaluating design ideation in previous studies (Hwang and Park 2018; Keshwani et al., 2017).

Two evaluators subjectively and independently evaluated the ideas via the novelty metrics. The evaluators used the traditional Likert Scale to rate the ideas (Figure 6). Both evaluators have bachelor's and master's degrees in industrial design. The condition of the experiments and the hypotheses were blind to the evaluators. The Pearson correlation coefficient of the evaluators is 0.756 and ICC (infraclass correlation coefficient) is 0.852 , which indicates substantial agreement on the novelty metric.

Is the idea Novel?
$\begin{array}{ccccc}1 & 2 & 3 & 4 & 5 \\ \begin{array}{l}\text { Strongly } \\ \text { Disagree }\end{array} & \text { Disagree } & \text { Neutral } & \text { Agree } & \text { Strongly Agree }\end{array}$

Figure 6. Rating scale for novelty evaluation

\subsection{Sketch examples}

Figure 7 shows one of the examples, which was evaluated as a highly novel idea (scored ' 5 ' in novelty) by both evaluators.

Through analysing the master student's sketch and text descriptions, we found that seven out of the ten design heuristics were utilized, as follows (the DHS utilised were numbers in brackets by \#).

Design Concept Description: The W-Drone is an integrated Drone meeting system (\#1 Adding Drone Technology), which addresses the teleconference low efficiency, especially in architecture and industrial design area. The W-Drone can control the Drone remotely and intelligently (\#8 Manage and Control Remotely, \#7 Adding Smart Functions), so as to help stakeholders to watch the whole design and detail design work through different angles and heights. The W-Drone has a sound and light system (\#4 Utilizing Lights and Sounds), which can allow users to send themselves voice to the opposite side. The W-Drone has a foldable structure (\#5 Utilizing Foldable Structure) so that it can be stored in a small space. W-Drone also provides Sharing Function (\#6 Adding Sharing Service). Every company's staff can use the W-Drone if it is available. Besides, W-Drone provides projection display technology (\#3 
Utilizing Display Technology), which can display opposite side images. For example, stakeholders draw sketches and give some reference images to designers. Most importantly, these functions will enhance the experience in collaboration and communication. W-Drone will save costs and time significantly. The volunteers' comments were as follows:

"In the beginning, I saw this design task and I thought it is very hard for me. I use brainstorming to think this design task. Unfortunately, I still can't think of any good ideas. But when I saw these design heuristics, in 10 mins I understood them. Then, I could quickly come out ideas for tackling this design problem."

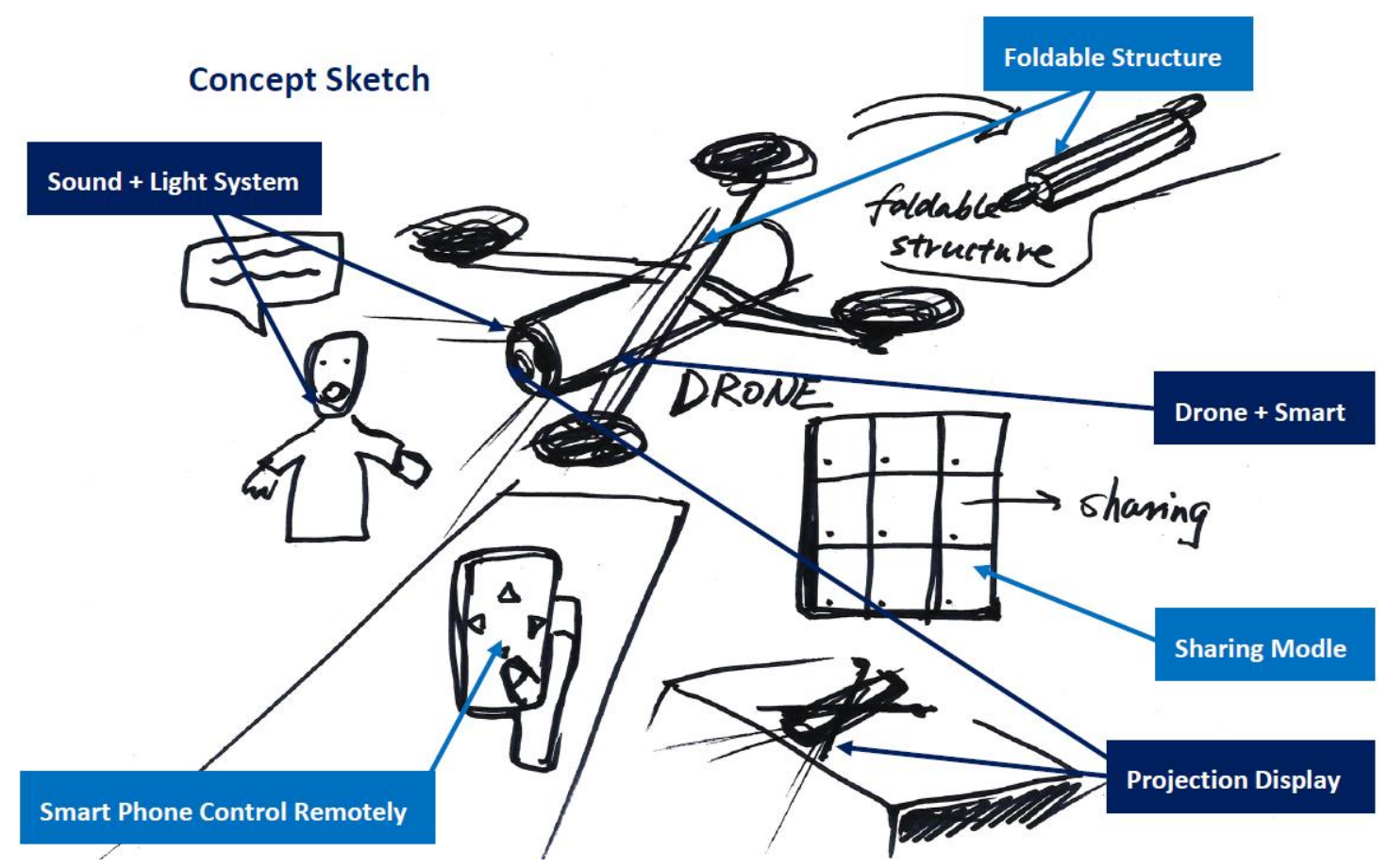

Figure 7. Sketches from the evaluation

\subsection{Results}

Table 1 illustrates the three volunteers' idea sketches, textual descriptions, mean novelty values and the DHS used. One of the volunteers generated six ideas within 30 minutes and showed a range of diverse ideas (No.1 to No.6). Five ideas (45\%) were scored 3; six ideas were above 3 (Figure 8). The mean novelty value is 3.59 .

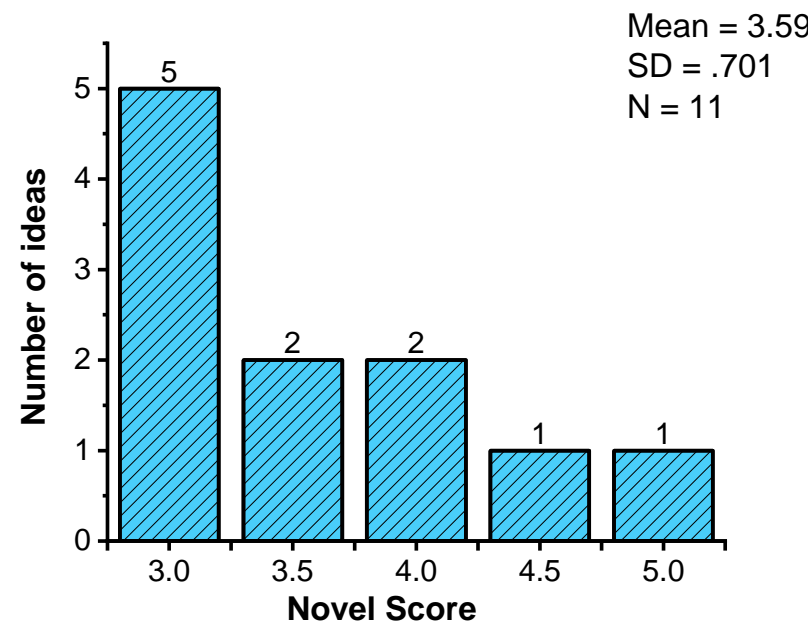

Figure 8. The novel score and number of ideas 
Table 1. Ideas generated using the new DHS

\begin{tabular}{|c|c|c|c|}
\hline $\begin{array}{l}\text { DHS } 2 \\
\text { DHS } 3\end{array}$ & 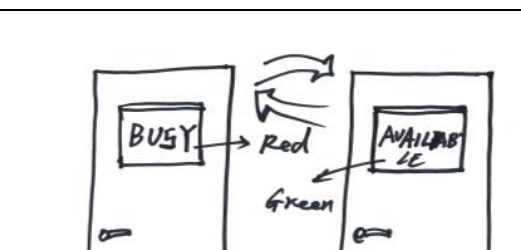 & DHS 4 & Reminder Sound/music \\
\hline $\begin{array}{l}\text { No. } 1 \\
M=3\end{array}$ & Digital notice outside the door & $\begin{array}{l}\text { No. } 2 \\
M=3.5\end{array}$ & $\begin{array}{l}\text { Smart white board with sound/music } \\
\text { reminders }\end{array}$ \\
\hline DHS 3 & $\begin{array}{l}\text { Ae the begining } \\
\text { of the dag the end } \\
\text { of the day }\end{array}$ & $\begin{array}{l}\text { DHS } 3 \\
\text { DHS } 7\end{array}$ & $d$ \\
\hline $\begin{array}{l}\text { No. } 3 \\
M=3\end{array}$ & Digital "to do" list with reward stars & $\begin{array}{l}\text { No. } 4 \\
M=4\end{array}$ & $\begin{array}{l}\text { Open kitchen, "call for brainstorming" board } \\
\text { to organise informal meetings }\end{array}$ \\
\hline DHS 8 & $\begin{array}{l}\text { Then } \\
\text { START }\end{array}$ & DHS 9 & 15 mins \\
\hline $\begin{array}{l}\text { No. } 5 \\
M=3\end{array}$ & $\begin{array}{l}\text { Remote notice board to update } \\
\text { information }\end{array}$ & $\begin{array}{l}\text { No. } 6 \\
M=4.5\end{array}$ & $\begin{array}{l}\text { Digital sand timer to enable change of time } \\
\text { setting and cancel (to start from zero) }\end{array}$ \\
\hline DHS 3 & worker & DHS 6 & prospeople. \\
\hline $\begin{array}{l}\text { No. } 7 \\
M=3.5\end{array}$ & $\begin{array}{l}\text { AR in manufacturing to provide } \\
\text { guidance and training for workers }\end{array}$ & $\begin{array}{l}\text { No. } 8 \\
M=3\end{array}$ & $\begin{array}{l}\text { Sharing service in food industry to minimise } \\
\text { food waste }\end{array}$ \\
\hline DHS 6 & 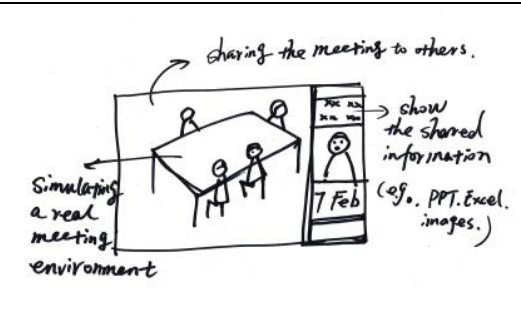 & $\begin{array}{l}\text { DHS } 3 \\
\text { DHS } 10\end{array}$ & 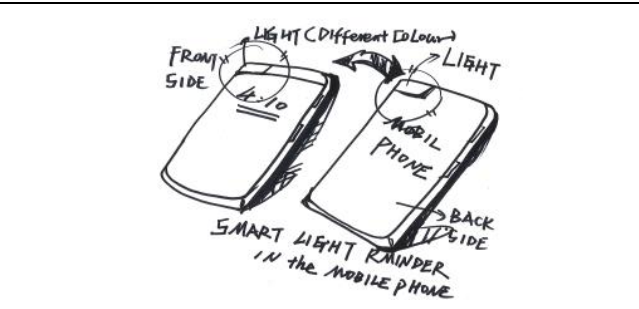 \\
\hline $\begin{array}{l}\text { No. } 9 \\
M=4\end{array}$ & $\begin{array}{l}\text { A software that could enable a } \\
\text { group meeting. Participants can see } \\
\text { each other. Sharing of } \\
\text { computer/phone screen. Simulating } \\
\text { a real meeting environment }\end{array}$ & $\begin{array}{l}\text { No. } 10 \\
M=3\end{array}$ & $\begin{array}{l}\text { Both sides have information light, and a } \\
\text { screen for displaying time. Different colours } \\
\text { show the different importance or agency of } \\
\text { the information. Users can choose to reply } \\
\text { immediately or not }\end{array}$ \\
\hline
\end{tabular}




\section{Discussion and conclusion}

By studying the 998 RedDot award-winning designs, we have extracted 10 specific Design Heuristics for the Digital Era which will aid designers to create innovative ideas in the conceptual design stage. The initial evaluation with four volunteers suggests the potential of the design heuristics. When brainstorming could not support concept generation, the new DHS proved useful in helping generate concepts with diverse 'novel' features (see the example in Fig 7). When time was limited, the DHS proved effective in inspiring different ideas, with moderate or higher levels of novelty. One volunteer commented:

"The design brief is quite abstract and it is difficult to come out of initial concepts. So I started to look at the DHS. The titles (of the DHS) and the images inspired me to generate concepts. I actually relied on these DHS, without of them I would have not generated six ideas in 30 minutes."

It indicates that industrial design practitioners including teachers and students can get benefits from the DHS for generating novel and diverse ideas. Our study has suggested the potential of the new design heuristics in supporting quick and diverse concept generation. More comprehensive evaluation, larger samples, and comparison experiments (e.g., DHS vs. Brainstorming) are needed to further assess the usefulness and usability of the design heuristics, and user feedback needs to be gathered to refine the communication of the heuristics. In the future studies, the new design heuristics should be compared with existing ones as well, such as SCAMPER (Eberle, 1971), TRIZ (Ilevbare et al., 2013), and 77 Design Heuristics (Yilmaz et al., 2016).

\section{Acknowledgement}

We thank the volunteers. The PhD study is supported by the Chinese Scholarship Council.

\section{References}

Bazeley, P. and Jackson, K. (2013), Qualitative data analysis with NVivo, SAGE publications limited.

Bloesch-Paidosh, A. and Shea, K. (2019), "Design Heuristics for Additive Manufacturing Validated Through a User Study”, Journal of Mechanical Design, Vol. 141 No. 4. https://doi.org/10.1115/1.4041051

Bruseberg, A. and McDonagh-Philp, D. (2002), "Focus groups to support the industrial/product designer: a review based on current literature and designers' feedback”, Applied Ergonomics, Vol. 33 No. 1, pp. 27-38. https://doi.org/10.1016/S0003-6870(01)00053-9

Calabretta, G. and Kleinsmann, M. (2017), "Technology-driven evolution of design practices: envisioning the role of design in the digital era”, Journal of Marketing Management, Vol. 33 No. 3-4, pp. 292-304. https://doi.org/10.1080/0267257x.2017.1284436

Castillo, C. (2005), "Effective web crawling”, Acm sigir forum, Acm New York, NY, USA, pp. 55-56.

Design Council (2018a), The Design Economy 2018: The State of Design in the UK, London, UK.

Design Council (2018b), Understanding Design-Intensive Innovation: A literature review [online], Design Council, London, UK.

Daly, S.R. et al. (2012), "Design Heuristics in Engineering Concept Generation", Journal of Engineering Education, Vol. 101 No. 4, pp. 601-629. https://doi.org/10.1002/j.2168-9830.2012.tb01121.x

Dove, G. et al. (2017), "UX Design Innovation: Challenges for Working with Machine Learning as a Design Material", Proceedings of the 2017 Acm Sigchi Conference on Human Factors in Computing Systems (Chi'17), pp. 278-288. https://doi.org/10.1145/3025453.3025739

Eberle, R.F. (1971), "Scamper: games for imagination development”, BuffaloN. YDOK.

Edhlund, B. and McDougall, A. (2019), Nvivo 12 Essentials, Lulu.com.

Han, J. et al. (2019), "Three driven approaches to combinational creativity: Problem-, similarity- and inspirationdriven", Proceedings of the Institution of Mechanical Engineers Part C-Journal of Mechanical Engineering Science, Vol. 233 No. 2, pp. 373-384. https://doi.org/10.1177/0954406217750189

Hwang, D. and Park, W. (2018), "Design heuristics set for X: A design aid for assistive product concept generation”, Design Studies, Vol. 58, pp. 89-126. https://doi.org/10.1016/j.destud.2018.04.003

Ilevbare, I.M., Probert, D. and Phaal, R. (2013), "A review of TRIZ, and its benefits and challenges in practice", Technovation, Vol. 33 No. 2-3, pp. 30-37. https://doi.org/10.1016/j.technovation.2012.11.003

Jansson, D.G. and Smith, S.M. (1991), “Design fixation”, Design studies, Vol. 12 No. 1, pp. 3-11. 
Keshwani, S. et al. (2017), "Comparing novelty of designs from biological-inspiration with those from brainstorming”, Journal of Engineering Design, Vol. 28 No. 10-12, pp. 654-680. https://doi.org/10.1080/ 09544828.2017 .1393504

Kirton, M.J. (2004), Adaption-innovation: In the context of diversity and change, Routledge.

Osborn, A.F. (1963), Applied imagination; principles and procedures of creative problem-solving: principles and procedures of creative problem-solving, Scribner.

Purcell, A.T. and Gero, J.S. (1996), "Design and other types of fixation”, Design studies, Vol. 17 No. 4, pp. 363-383.

RedDot. (2020), Red Dot Concept Award Judging Criteria. [online] Red Dot Award: Design Concept. Available at: https://www.red-dot.org/design-concept/jury/ (accessed 05.02.2020).

Self, J.A. (2014), "Mind the Gap: Perceptions of Design Awards from the Wild", International Journal of Design, Vol. 8 No. 3, pp. 123-138.

Simon, H.A. (1996), The sciences of the artificial, MIT press.

Tsenn, J. et al. (2014), “The effects of time and incubation on design concept generation”, Design Studies, Vol. 35 No. 5, pp. 500-526. https://doi.org/10.1016/j.destud.2014.02.003

Vasconcelos, L.A. and Crilly, N. (2016), "Inspiration and fixation: Questions, methods, findings, and challenges", Design Studies, Vol. 42, pp. 1-32. https://doi.org/10.1016/j.destud.2015.11.001

Wang, H.-H. (2016), "Winning formulas for metaphor design: A case study of design competitions", DS 84: Proceedings of the DESIGN 2016 14th International Design Conference, pp. 1957-1964.

Yilmaz, S. et al. (2016), "Evidence-based design heuristics for idea generation”, Design Studies, Vol. 46, pp. 95124. https://doi.org/10.1016/j.destud.2016.05.001

Yilmaz, S., Seifert, C.M. and Gonzalez, R. (2010), "Cognitive heuristics in design: Instructional strategies to increase creativity in idea generation", Ai Edam-Artificial Intelligence for Engineering Design Analysis and Manufacturing, Vol. 24 No. 3, pp. 335-355. https://doi.org/10.1017/S0890060410000235

Yilmaz, S. et al. (2015), "How do designers generate new ideas? Design heuristics across two disciplines", Design Science, Vol. 1, p. e4. https://doi.org/10.1017/dsj.2015.4

Yilmaz, S. et al. (2016), "Design Heuristics in Innovative Products", Journal of Mechanical Design, Vol. 138 No. 7. https://doi.org/10.1115/1.4032219

Yilmaz, S. et al. (2011), "Creativity through design heuristics: A case study of expert product design", Design Studies, Vol. 32 No. 4, pp. 384-415. https://doi.org/10.1016/j.destud.2011.01.003 